\title{
TIA-Treatment: Stroke Units versus General Wards Mono-Center Study
}

Mohamed Al-Khaled ${ }^{1}$, Haneen Awwad ${ }^{2}$, Christine Matthis ${ }^{3}$ and Toralf Brüning ${ }^{1}$

${ }^{1}$ Department of Neurology, University of Lubeck, Lubeck, Germany

${ }^{2}$ All Saints University, Chicago, USA

3 Institute of Social Medicine, University of Lübeck, Lübeck, Germany

"Corresponding author: Mohamed Al-Khaled, Department of Neurology, University of Lubeck Ratzeburger Allee 160, 23538 Lubeck, Germany, Tel: 00494515002932; Fax: 00494515005457; E-mail: Mohamed.al-khaled@neuro.uni-luebeck.de

Received date: Sep 17, 2014, Accepted date: Dec 06, 2014, Published date: Dec 12, 2014

Copyright: (c) 2014 Al-Khaled M, et al. This is an open-access article distributed under the terms of the Creative Commons Attribution License, which permits unrestricted use, distribution, and reproduction in any medium, provided the original author and source are credited.

\begin{abstract}
Background and Purpose: Transient ischemic attack (TIA) is associated with a high short-term risk of stroke. The aim of this study is to compare the diagnostic evaluation, therapeutic procedures, and secondary prevention strategies in TIA patients who were directly admitted to a stroke unit (SU) and received semi-intensive care in comparison to those who were treated in general wards (GW) in a mono-center study.

Methods: During a 6-year period (2008-2013), 1114 TIA patients who were admitted to the Department of Neurology at the University of Schleswig-Holstein, campus Lübeck, were evaluated in a mono-center study.

Results: A total of 604 (57\%) TIA patients were admitted to the SU, whereas 453(37\%) patients were admitted to the GW. Patients with a TIA who were undergoing treatment in an SU were significantly younger (69.1 vs. 71.0 years; $P=0.023$ ) and had higher rates of paresis (30.1 vs. $21.8 \% ; p<0.003)$, hypertension $(79.7$ vs. $74.3 \% ; P=0.042)$ and hypercholesterolemia ( 57.2 vs. $46.7 \%$; $P=0.001$ ) than those who were undergoing treatment in the $G W . P a t i e n t s$ in SUs received significantly higher rates of carotid revascularization for symptomatic carotid stenosis (5.8\% vs. $0.4 \%$; $P<0.001$ ), dysphagia screening (47.6 vs. $27.3 \%$; $P<0.001)$, speech therapy $(33.0$ vs. $14.8 \% ; P<0.001)$, and physiotherapy $(51.0$ vs. $37.2 \% ; \mathrm{P}<0.001)$ in comparison to those admitted to GWs. The TIA etiology; cardioembolism was significantly more common (18.0 vs. $12.7 \%$; $P=0.037$ ) in patients treated in stroke unit, whereas the undetermined etiology of TIA was significantly less diagnosed in patients who were admitted to SI-SU than those treated in CC (50. vs. 58\%; $P=0.037)$. Carotid revascularization for symptomatic stenosis was more performed in patients who underwent stroke unit care than those who were treated in general wards $(5.8$ vs. $0.4 \%$, $\mathrm{P}<0.001)$.
\end{abstract}

Conclusion: TIA-Treatment in the SU appears to be correlated with more diagnostic and therapeutic procedures in comparison to care in general wards.

Keywords: TIA; Stroke; Stroke unit; General wards; Diagnostic evaluation; Secondary prevention

\section{Introduction}

Transient ischemic attack (TIA) is a marker for an unstable condition that is associated with high short-term risk of stroke [1]. The diagnostic evaluation of etiology and the therapeutic procedures used in patients suffering from TIA vary substantially worldwide. The results of several trials have indicated that TIA portends an increased risk of stroke and that this risk of stroke after TIA is highest during the early period after the index event [2-5]. Other studies revealed that the risk of stroke after TIA is ranging between $1.1 \%$ to $12.8 \%$ over a period of 7 days, reaching $21.4 \%$ at 1 year [5-7]. These findings underscore the need for the rapid evaluation of etiology and the implementation of secondary prevention strategies immediately after the TIA event. Several randomized controlled studies in different countries have shown the effectiveness of stroke unit (SU) care for stroke patients [8-11]. Our research group previously investigated the effectiveness of the management of patients with TIA who were admitted to departments of neurology with a stroke unit in comparison to those who were treated in departments of internal medicine without a stroke unit, $[12,13]$ but there are no published data comparing the diagnostic evaluation, therapeutic procedures, and secondary prevention strategies that are used in the treatment of patients suffering from TIA and who are admitted initially to a stroke unit (SU) with those who are admitted directly to general wards GW in the same hospital. International guidelines differ in their recommendations on how to manage patients with TIA. International guidelines recommend hospitalizing patients suffering from TIA depending on presenting time (within 72 hours) and ABCD2 score $(\geq 3),[14,15]$ whereas other guidelines recommend that all patients suffering from TIA should be treated in an SU as soon as possible, independent from the ABCD2 score [16]. However, according to German recommendations on stroke treatment, all patients suffering from TIA should receive care at a stroke unit and get transferred to a hospital, as quickly as possible. 


\section{Methods}

\section{Study design}

We aimed in the present study to investigate the management of TIA in a mono-center study. The study was a part of the ongoing benchmarking project (QugSS [German: Qualitatsgemeinschaft Schlaganfallversorgung in Schleswig-Holstein]), which was previously described $[17,18]$. The QugSS-register is a population-based study including 15 hospitals in Schleswig-Holstein in Germany, we previously compared the impact of stroke unit care at the departments of neurology to conventional care in the departments of internal Medicine in patients suffering TIA in accordance to the WHO definition (neurological symptoms of TIA regress within 24 hours) [19].

To highlight the stroke unit care and to avoid bias selection, we included only patients suffering from TIA who were admitted to the Department of Neurology at the University hospital of Schleswig-
Holstein, campus Lubeck. All TIA patients underwent a standardized TIA evaluation and treated form the same physician's team. The TIA definition used in the present study was in accordance to the new (tissue-based) definition [15].

All patients over the age of 18 years who were suffering from TIA were recruited during a study period of 6 years (2008 to 2013). Inclusion criteria were TIA in accordance with the tissue-based definition (transient neurological symptoms without infarct evidence on the brain imaging including CCT and DWI-MRI, and admission to the Department of Neurology at the University of Lubeck within 48 hours of symptom onset. Exclusion criteria were admission to the hospital after 48 hours following symptom onset and patients who were admitted with suspected TIA, but diagnosed with other neurological disorders. The documentation and data collection followed a uniform study manual. Baseline characteristics at admission (Table 1) were recorded. A medical doctor who was not involved in the treatment of the patients checked the data. The study was approved by the local ethics Committee.

\begin{tabular}{|c|c|c|c|}
\hline Baseline characteristics & $\begin{array}{l}\text { Stroke unit } \\
\mathrm{N}=604\end{array}$ & $\begin{array}{l}\text { General wards } \\
N=453\end{array}$ & $P$ \\
\hline Age, mean (SD) & $69.1(13)$ & $71.0(14)$ & 0.023 \\
\hline Female sex & $273(45.3)$ & $236(51)$ & 0.069 \\
\hline $\begin{array}{l}\text { Duration of symptoms; }<1 \text { hour } \\
1 \text { to } 24 \text { hours }\end{array}$ & $\begin{array}{l}235(39.4) \\
362(60.7)\end{array}$ & $\begin{array}{l}190(42.0) \\
262(58.0)\end{array}$ & 0.3 \\
\hline $\begin{array}{l}\text { TIA's symptoms; Paresis } \\
\text { Aphasia } \\
\text { Dysarthria }\end{array}$ & $\begin{array}{l}178(30.1) \\
106(18) \\
92(15.6)\end{array}$ & $\begin{array}{l}100(21.8) \\
71(15.6) \\
63(13.8)\end{array}$ & $\begin{array}{l}0.003 \\
0.3 \\
0.4\end{array}$ \\
\hline $\begin{array}{l}\text { Medical history; } \\
\text { Hypertension } \\
\text { Diabetes mellitus } \\
\text { Hypercholesterolemia } \\
\text { Previous stroke } \\
\text { Atrial fibrillation } \\
\text { Antiplatelet therapy before TIA }\end{array}$ & $\begin{array}{l}470(79.7) \\
145(24.5) \\
329(57.2) \\
171(29.2) \\
104(17.8) \\
256(43.8)\end{array}$ & $\begin{array}{l}339(74.3) \\
98(21.6) \\
211(46.7) \\
122(27.0) \\
71(15.7) \\
195(43.2)\end{array}$ & $\begin{array}{l}0.042 \\
0.2 \\
0.001 \\
0.4 \\
0.3 \\
0.8\end{array}$ \\
\hline $\begin{array}{l}\text { TIA-Etiology (TOAST); } \\
\text { Cardioembolism } \\
\text { Large-artery atherosclerosis } \\
\text { Small-artery occlusion } \\
\text { Other determined etiology } \\
\text { Undetermined etiology }\end{array}$ & $\begin{array}{l}84(18.0)^{\star} \\
70(15.0) \\
55(11.8) \\
24(5.2) \\
233(50.0)^{\star}\end{array}$ & $\begin{array}{l}42(12.7) \\
57(17.2) \\
28(8.5) \\
11(3.3) \\
193(58.3)\end{array}$ & 0.038 \\
\hline
\end{tabular}

Table 1: Baseline Characteristics in TIA patients treated in stroke unit compared to those with general wards. Value in $\mathrm{n}$ and (\%) unless otherwise indicated. ${ }^{*}$ Differences after a Bonferroni correction are significant.

\section{Treatment concept}

The stroke unit care provides semi-intensive care and combines advanced early monitoring of vital parameters and offer treatments based on pathophysiology of patients suffering from TIA. Here, a neurologist with stroke experience is present 24 hours a day, in addition to specialized staff. Patients should then have their blood pressure, electrocardiography, and blood oxygenation monitored for at least 24 hours-optimally 72 hours or longer, based on the pathophysiology of TIA - and fever, blood sugar, and fluid balance should also be controlled. Patients receiving SU care should not be fed orally until dysphagia testing is performed. In cases where dysphagia is present, feeding routes are recommended. Patients' neurological status and National Institutes of Health Stroke Scale (NIHSS) score should be determined every 6 hours by a neurologist or by a doctor who has experience in treating stroke. The evaluation of etiology must be performed immediately during the monitoring period in the SU. If 
Page 3 of 5

cardiac diagnostic testing reveals cardioembolic source of TIA, patients should be administered oral anticoagulants. The SU team typically consists of neurologists with stroke experience working in cooperation with neuroradiologists. A specialized medical and nursing team should immediately implement physiotherapy and initiate speech therapy and ergotherapy as early as possible. All radiological investigations, such as cranial computed tomography (CCT), magnetic resonance imaging (MRI), magnetic resonance angiography, and transesophageal echocardiography as well as ultrasound sonography of the arteries of the neck and brain, should be readily performed when necessary.

\section{Statistics}

We analyzed the data with an SPSS software program (version: PASW Statistics 22). The mean, standard deviation, and percentage values were used to describe the data. We performed a $\chi^{2}$ test to calculate the correlation between parametric variables, and a $t$ test and a Mann-Whitney $U$ test between nonparametric variables. A P value less than 0.05 was considered statistically significant.

\section{Results}

A total of 1114 consecutive patients suffering from TIA (mean age, $70.5 \pm 13$ years; $49.9 \%$ women) with an NIHSS score (mean, $1.4 \pm 2.5$ ) at NIHSS score (mean, $1.4 \pm 2.5$ ) at admission were included in this study. A total of 604 TIA Patients were admitted to the stroke unit and underwent semi-intensive care for at least 24 hours, whereas $37 \%$ patients were admitted directly to the GW.

Patients with TIA who were undergoing treatment in a SU were significantly younger (69.1 vs. 71.0 years; $\mathrm{P}=0.023)$ and had higher rates of paresis as TIA symptoms (30.1 vs. $21.8 \%$; $<<0.003)$, hypertension ( 79.7 vs. $74.3 \% ; \mathrm{P}=0.042)$ and hypercholesterolemia $(57.2$ vs. $46.7 \% ; \mathrm{P}=0.001$ ) than those who were undergoing treatment in the GW (Table 1). The findings of the diagnostic evaluations (cardioembolic source) were found to be significantly higher in patients who were monitored in the SU compared to those in the GW, whereas the undetermined etiology of TIA was less common in patients who received TIA work up in the SU (Table 1).

The diagnostic and therapeutic procedures were shown in table 2 . The carotid revascularization, dysphagia testing, physiotherapy, and speech therapy were performed at higher rates in patients who were admitted to the SU than those in the GW (Table 2).

\begin{tabular}{|l|l|l|l|}
\hline & $\begin{array}{l}\text { Stroke unit } \\
\text { N=604 }\end{array}$ & $\begin{array}{l}\text { General wards } \\
\text { N=463 }\end{array}$ & P \\
\hline CCT & $583(98.5)$ & $439(96.9)$ & 0.08 \\
\hline MRI & $257(45.2)$ & $196(44.3)$ & 0.7 \\
\hline $\begin{array}{l}\text { Duplex sonography, } \\
\text { extracranial } \\
\text { transcranial }\end{array}$ & $566(98.1)$ & $428(96.2)$ & 0.063 \\
\hline Dysphagia screening & $545(94.1)$ & $411(92.8)$ & 0.3 \\
\hline OAC after TIA & $272(47.6)$ & $121(27,3)$ & $<0.001$ \\
\hline AT after TIA & $115(19.5)$ & $69(15.1)$ & 0.062 \\
\hline CR after TIA & $485(81.5)$ & $389(85.1)$ & 0.12 \\
\hline Physiotherapy & $34(5.8)$ & $2(0.4)$ & $<0.001$ \\
\hline Speech therapy & $288(51.0)$ & $167(37.2)$ & $<0.001$ \\
\hline
\end{tabular}

Table 2: Diagnostic and therapeutic procedures of TIA patients during hospitalization CCT, cranial computed tomography; AT, Antiplatelet therapy; OAC, oral anticoagulation; CR; carotid revascularization. Data recorded in $\mathrm{n}(\%)$.

The length of hospitalization for patients in the SU was longer than that of those in the GW (6.0 vs. 5.5 days; $\mathrm{P}=0.004)$. Complications during the hospital stay did not differ between the two groups (Table 3).

\begin{tabular}{|l|l|l|l|}
\hline Complications & $\begin{array}{l}\text { Stroke unit } \\
\mathbf{N}=\mathbf{6 0 4}\end{array}$ & $\begin{array}{l}\text { General wards } \\
\mathbf{N}=\mathbf{4 6 3}\end{array}$ & $\mathbf{P}$ \\
\hline Pneumonia & $8(1.7)$ & $10(1.7)$ & 0.9 \\
\hline Urinary tract infection & $21(3.5)$ & $10(2.2)$ & 0.2 \\
\hline
\end{tabular}

\begin{tabular}{|l|l|l|l|}
\hline Fall during hospitalization & $3(0.5)$ & $3(0.6)$ & 0.7 \\
\hline Confusion & $8(0.6)$ & $26(1.1)$ & 0.8 \\
\hline Cardiovascular complications & $1(0.2)$ & $3(0.6)$ & 0.2 \\
\hline Other complications & $18(3.0)$ & $14(3.0)$ & 0.9 \\
\hline
\end{tabular}

Table 3: Complications after during hospital Stay; Value are in $\mathrm{n}$ and (\%). 


\section{Discussion}

TIA symptoms are frequently unspecific and are not consistently classified as vascular events, that may be associated with high risk of stroke, [20-22] the primary aim of the treatment of TIA is the protection of patients from disability and mortality caused by a potentially forthcoming stroke, which is carried out after the first event and through the implementation of investigations to evaluate the etiology and to eliminate the causes of TIA. The rapid evaluation and early initiation of treatment after a TIA can reduce the risk of stroke following TIA remarkably [23-25]. Furthermore, the implementation of secondary prevention strategies can be started immediately after the TIA event. Edlow and colleagues [26] found that only 54\% of patients suffering from TIA who visited emergency departments were admitted to hospital. This finding suggests that $46 \%$ of patients suffering from TIA obtained an evaluation of etiology later in ambulatory care. SUs have been established to treat patients with stroke, but the ways of managing TIAs often vary and depend on the severity of the neurological deficits and findings of the brainimaging $[15,16,25]$. The hospitalization of TIA patients has been found to correlate with high rates of adherence to secondary prevention strategies and to reduce the stroke risk following TIA event, which is the main goal of TIA Management $[27,28]$.

According to the diagnostic evaluation, the cardioembolic sources of TIA were detected more in patients in the SU than those in the GW and the undermined etiology of TIA was found to be less common in patients who were admitted to a stroke unit.

The hospital stay for patients in the SU was longer than for those in the GW. This could have been caused by the higher frequency of patients in the SU that underwent a carotid revascularization after the detection of a carotid stenosis or an implementation of oral anticoagulant after findings of a cardioembolic source [29]. Another reason for longer hospitalization time in patients who are been treated in the SU might be the need for monitoring for 24 hours at the very least.

In summary, this study shows that diagnostic evaluation, therapeutic procedures, and secondary prevention strategies used in treating patients with TIA, and are carried out more often in patients who were admitted to a stroke unit than in general wards that may prevent TIA patients from a disabling stroke. Further prospective randomized studies are needed.

\section{References}

1. Dennis M, Bamford J, Sandercock P, Warlow C (1990) Prognosis of transient ischemic attacks in the Oxfordshire Community Stroke Project. Stroke 21: 848-853.

2. Brown RD Jr, Petty GW, O'Fallon WM, Wiebers DO, Whisnant JP (1998) Incidence of transient ischemic attack in Rochester, Minnesota, 1985-1989. Stroke 29: 2109-2113.

3. Rothwell PM, Warlow CP (2005) Timing of TIAs preceding stroke: time window for prevention is very short. Neurology 64: 817-820.

4. Johnston SC, Gress DR, Browner WS, Sidney S (2000) Short-term prognosis after emergency department diagnosis of TIA. JAMA 284: 2901-2906.

5. Correia M, Silva MR, Magalhães R, Guimarães L, Silva MC (2006) Transient ischemic attacks in rural and urban northern Portugal: incidence and short-term prognosis. Stroke 37: 50-55.

6. Al-Khaled M, Eggers J2 (2014) Early hospitalization of patients with TIA: a prospective, population-based study. J Stroke Cerebrovasc Dis 23: 99-105.
7. Al-Khaled M, Matthis C, Eggers J (2012) Short-term risk and predictors of stroke after transient ischemic attack. J Neurol Sci 312: 79-81.

8. Candelise L, Gattinoni M, Bersano A, Micieli G, Sterzi R, et al. (2007) Stroke-unit care for acute stroke patients: an observational follow-up study. Lancet 369: 299-305.

9. Terént A, Asplund K, Farahmand B, Henriksson KM, Norrving B, et al. (2009) Stroke unit care revisited: who benefits the most? A cohort study of 105,043 patients in Riks-Stroke, the Swedish Stroke Register. J Neurol Neurosurg Psychiatry 80: 881-887.

10. Walter A, Seidel G, Thie A, Raspe H (2009) Semi-intensive stroke unit versus conventional care in acute ischemic stroke or TIA--a prospective study in Germany. J Neurol Sci 287: 131-137.

11. Govan L, Langhorne P, Weir CJ; Stroke Unit Trialists Collaboration (2007) Does the prevention of complications explain the survival benefit of organized inpatient (stroke unit) care?: further analysis of a systematic review. Stroke 38: 2536-2540.

12. Al-Khaled M, Matthis C, Seidel G (2013) The prognostic impact of the stroke unit concept after transient ischemic attack. Clin Neurol Neurosurg 115: 725-728.

13. Al-Khaled M, Matthis C, Eggers J (2013) The prognostic impact of the stroke unit care versus conventional care in treatment of patients with transient ischemic attack: a prospective population-based German study. J Vasc Interv Neurol 5: 22-26.

14. Johnston SC, Nguyen-Huynh MN, Schwarz ME, Fuller K, Williams CE, et al. (2006) National Stroke Association guidelines for the management of transient ischemic attacks. Ann Neurol 60: 301-313.

15. Easton JD, Saver JL, Albers GW, Alberts MJ, Chaturvedi S, et al. (2009) Definition and evaluation of transient ischemic attack: A scientific statement for healthcare professionals from the american heart association/american stroke association stroke council; council on cardiovascular surgery and anesthesia; council on cardiovascular radiology and intervention; council on cardiovascular nursing; and the interdisciplinary council on peripheral vascular disease. The american academy of neurology affirms the value of this statement as an educational tool for neurologists. Stroke 40: 2276-2293.

16. European Stroke Organisation (ESO) Executive Committee; ESO Writing Committee (2008) Guidelines for management of ischaemic stroke and transient ischaemic attack 2008. Cerebrovasc Dis 25: 457-507.

17. Matthis C, Raspe H (2011) [Quality Association for Acute Stroke Treatment Schleswig-Holstein (QugSS)]. Z Evid Fortbild Qual Gesundhwes 105: 376-382.

18. Al-Khaled M, Eggers J (2013) MRI findings and stroke risk in TIA patients with different symptom durations. Neurology 80: 1920-1926.

19. MARSHALL J (1964) THE NATURAL HISTORY OF TRANSIENT ISCHAEMIC CEREBRO-VASCULAR ATTACKS. Q J Med 33: 309-324.

20. Koudstaal PJ, Gerritsma JG, van Gijn J (1989) Clinical disagreement on the diagnosis of transient ischemic attack: is the patient or the doctor to blame? Stroke 20: 300-301.

21. Ferro JM, Falcão I, Rodrigues G, Canhão P, Melo TP, et al. (1996) Diagnosis of transient ischemic attack by the nonneurologist. A validation study. Stroke 27: 2225-2229.

22. Paul NL, Simoni M, Rothwell PM, Oxford Vascular S (2013) Transient isolated brainstem symptoms preceding posterior circulation stroke: A population-based study. Lancet Neurol. 12: 65-71.

23. Rothwell PM, Giles MF, Chandratheva A, Marquardt L, Geraghty O, et al. (2007) Effect of urgent treatment of transient ischaemic attack and minor stroke on early recurrent stroke (express study): A prospective population-based sequential comparison. Lancet 370: 1432-1442.

24. Perry JJ, Sharma M, Sivilotti ML, Sutherland J, Worster A, et al. (2014) A prospective cohort study of patients with transient ischemic attack to identify high-risk clinical characteristics. Stroke 45: 92-100.

25. Vora N, Tung CE, Mlynash M, Garcia M, Kemp S, et al. (2014) TIA triage in emergency department using acute MRI (TIA-TEAM): A feasibility and safety study. Int J Stroke . 
Citation: $\quad$ Al-Khaled M, Awwad H, Matthis C, Bruning T (2014) TIA-Treatment: Stroke Units versus General Wards Mono-Center Study. J Neurol Neurophysiol 5: 258. doi:10.4172/2155-9562.1000258

Page 5 of 5

26. Edlow JA, Kim S, Pelletier AJ, Camargo CA Jr (2006) National study on emergency department visits for transient ischemic attack, 1992-2001. Acad Emerg Med 13: 666-672.

27. Ovbiagele B, Saver JL, Fredieu A, Suzuki S, Selco S, et al. (2004) Inhospital initiation of secondary stroke prevention therapies yields high rates of adherence at follow-up. Stroke 35: 2879-2883.

28. Sundararajan V, Thrift AG, Phan TG, Choi PM, Clissold B, et al. (2014) Trends over time in the risk of stroke after an incident transient ischemic attack. Stroke 45: 3214-3218.
29. Al-Khaled M, Awwad H, Matthis C, Eggers J (2013) Stroke recurrence in patients with recently symptomatic carotid stenosis and scheduled for carotid revascularization. European journal of neurology: the official journal of the European Federation of Neurological Societies 20: 831-835. 